\title{
KEEFEKTIFAN MODEL PEMBELAJARAN KOOPERATIF TIPE SCRAMBLE DALAM KETERAMPILAN MENULIS KALIMAT BAHASA JERMAN SISWA KELAS XI SMA NEGERI 11 MAKASSAR
}

\author{
Sudarmi $^{1}$ dan Burhanuddin ${ }^{2}$ \\ Fakultas Bahasa dan Sastra, Universitas Negeri Makassar \\ E-mail1': sudarmi@gmail.com
}

\begin{abstract}
ABSTRAK
Tujuan penelitian ini adalah untuk memperoleh data dan informasi mengenai keefektifan model pembelajaran kooperatif tipe scramble dalam keterampilan menulis kalimat bahasa Jerman siswa kelas XI SMA Negeri 11 Makassar. Jenis penelitian ini adalah True experimental design. Data dianalisis dengan statistik inferensial. Pengambilan sampel dilakukan dengan teknik random sampling. Hasil analisis data yang diperoleh melalui uji-t adalah $t_{\text {hitung }}(11,24)>t_{\text {tabel }}(2,002)$ pada taraf signifikansi 0,05 . Hasil penelitian menunjukkan bahwa model ini efektif dalam meningkatkan keterampilan menulis kalimat bahasa Jerman siswa.
\end{abstract}

\section{Kata Kunci : Pembelajaran Kooperatif, Tipe Scramble, Keterampilan Menulis}

\begin{abstract}
The purpose of this study is to gain data and information related the effectiveness of cooperative learning model by using scramble type in increasing German language sentence writing skill of second level students in SMAN 11 Makassar. This study used true experimental design. Data was analyzed by using inferential statistic. Sample technique is random sampling. The data showed that $t_{\text {hitung }}(11,24)>t_{\text {tabel }}(2,002)$ on the significance level 0,05 . It means that this model is effective in increasing German language sentence writing skill of students.
\end{abstract}

\section{Keywords: Cooperative Learning, Scramble Type, Writing Skill}

\section{PENDAHULUAN}

Salah satu aspek kompetensi dalam pembelajaran bahasa Jerman adalah keterampilan menulis. Menulis merupakan keterampilan yang bersifat produktif yang harus dimiliki siswa agar terampil berkomunikasi secara tertulis. Dengan keterampilan tersebut, siswa dapat terampil dalam menggunakan kosa kata, ejaan, tanda baca yang tepat serta ragam kalimat yang variatif dalam menulis.
Keterampilan menulis bahasa Jerman siswa di sekolah pada umumnya masih tergolong rendah. Berdasarkan observasi penulis selama mengikuti PPL di SMAN 11 Makassar, metode pembelajaran bahasa Jerman masih didominasi oleh metode ceramah sehingga terkesan monoton. Selain itu, guru jarang memberikan tugas dan latihan yang menyentuh pada aspek menulis. 
Hal tersebut mengakibatkan
masih banyak siswa yang
mendapatkan hasil belajar yang
kurang memuaskan, terutama dalam
aspek keterampilan menulis. Hal ini
didukung oleh penelitian yang
dilakukan Suhardi (2008:38) yang
menemukan bahwa keterampilan
menulis bahasa Jerman siswa kelas XI SMAN 1 Anggeraja adalah 59,2\% (termasuk dalam kategori rendah). Begitu pula hasil penelitian yang dilakukan Fitriani (2010:32) yang menunjukkan bahwa kemampuan menulis karangan sederhana Bahasa Jerman kelas XI SMAN 5 Makassar masih tergolong kategori rendah dengan rata-rata nilai siswa $48,25 \%$. Hasil penelitian Efendi (2011:40) juga menunjukkan bahwa kemampuan menulis bahasa Jerman siswa kelas $\mathrm{X}$ SMAN 1 Polongbangkeng Utara termasuk kategori rendah dengan skor rata-rata nilai siswa adalah $53,42 \%$.

Melihat rendahnya hasil-hasil penelitian keterampilan menulis siswa dalam mata pelajaran bahasa Jerman, maka seorang pengajar perlu menggunakan model yang lebih efektif agar siswa termotivasi dalam belajar. Salah satu model pembelajaran yang dinilai efektif dan mampu memotivasi belajar siswa dalam belajar bahasa Jerman adalah model pembelajaran kooperatif tipe scramble.

Keefektifan penggunaan dari model pembelajaran kooperatif tipe scramble didukung dengan penelitian yang dilakukan oleh Hamonangan (2013) menunjukkan bahwa penerapan model pembelajaran kooperatif tipe scramble, dapat meningkatkan hasil belajar siswa pada mata pelajaran PKN. Selain itu berdasarkan hasil penelitian yang dilakukan oleh Alfrida (2014) menunjukkan bahwa penggunaan model pembelajaran kooperatif tipe scramble dapat membantu siswa dalam menguasai strukturen dengan skor rata-rata siswa adalah 9,06. Diharapkan penggunaan model tersebut dapat memotivasi siswa dalam belajar bahasa Jerman serta membantu siswa dalam menulis kalimat bahasa Jerman.

Model ini merupakan sebuah model pembelajaran yang menggunakan metode berbentuk permainan yang dilakukan secara berkelompok dengan menyusun kembali kata-kata atau kalimatkalimat yang telah diacak terlebih dahulu. Melalui model pembelajaran kooperatif tipe scramble, siswa diharapkan mampu berperan aktif dalam pembelajaran serta melatih siswa dalam menguatkan pemahaman mereka dalam pembelajaran.

\section{PEMBELAJARAN KOOPERATIF TIPE SCRAMBLE}

Pembelajaran kooperatif tipe scramble merupakan salah satu model pembelajaran yang melibatkan beberapa siswa dalam kelompok untuk bekerja sama menjawab pertanyaan yang diajukan oleh guru dengan cara menyusun huruf menjadi kata, kata menjadi kalimat, atau kalimat yang teracak menjadi sebuah paragraf yang utuh dan bermakna. 
Model scramble dikemukakan oleh Komalasari (2013:84) bahwa scramble merupakan model pembelajaran yang mengajak siswa mencari jawaban tehadap suatu pertanyaan atau pasangan dari suatu konsep secara kreatif dengan cara menyusun huruf-huruf yang disusun secara acak sehingga membentuk suatu jawaban/pasangan konsep yang dimaksud. Hamonangan (2013:2) berpendapat model pembelajaran kooperatif tipe scramble merupakan sebuah upaya pembelajaran yang melibatkan diskusi siswa dalam menemukan jawaban yang tepat dengan cermat sehingga siswa merasa belajar bukan sebuah beban dan merasa tertantang untuk memecahkan soal yang diberikan. Demikian pula halnya menurut Suyatno (2009) scramble merupakan salah satu tipe pembelajaran yang disajikan dalam bentuk kartu. Sedangkan menurut Taufina (2011:162) model scramble merupakan modifikasi dari metode tanya jawab yang merupakan kolaborasi dengan menggunakan lembar kerja yang jawabannya di acak susunannya.

Berdasarkan pendapat yang dikemukakan oleh para ahli di atas, maka dapat disimpulkan bahwa model pembelajaran kooperatif tipe scramble merupakan model pembelajaran yang menekankan kerjasama siswa dalam belajar melalui metode menjawab pertanyaan atau soal dengan jawaban yang berupa huruf, kata, atau kalimat yang diacak sehingga menjadi kata, kalimat, atau paragrap yang utuh dan bermakna.

Alur model pembelajaran kooperatif tipe scramble dimulai dengan membagi para siswa dalam beberapa kelompok, selanjutnya guru membagikan kartu soal dan kartu jawaban pada setiap kelompok. Kartu soal sudah dalam keadaan utuh tapi kartu jawaban masih dalam keadaan rumpang atau teracak, jadi siswa bekerja sama dalam kelompok untuk menyusun potongan-potongan kata tersebut menjadi kalimat yang utuh dan tepat tentunya dengan melihat kartu soal.

Langkah-langkah model pembelajaran kooperatif tipe scramble menurut Artini, dkk (2014:4) ada beberapa tahap antara lain:

1. menyampaikan tujuan dan memotivasi siswa;

2. menyajikan Informasi;

3. mengorganisasi siswa ke dalam kelompok-kelompok belajar, selanjutnya membagikan kartu soal dan kartu jawaban pada kelompok;

4. mengerjakan kartu soal secara berkelompok;

5. memberikan penghargaan; dan

6. evaluasi.

Suatu model pembelajaran yang diterapkan pada saat proses belajar mengajar berlangsung tentu tidak ada yang sempurna. Begitu pula dengan model pembelajaran kooperatif tipe scramble yang memiliki kelebihan dan kekurangan. Artini, dkk (2014:4) menjelaskan kelebihan dan kekurangan dari model ini sebagai berikut: 


\begin{tabular}{llll} 
No. & \multicolumn{1}{c}{ Kelebihan } & \multicolumn{1}{c}{ Kekurangan } \\
\hline 1. & $\begin{array}{l}\text { Mendorong siswa lebih aktif dan } \\
\text { cekatan }\end{array}$ & Siswa kurang berpikir kritis \\
2. & $\begin{array}{l}\text { Membantu siswa memahami konsep- } \\
\text { konsep yang sulit }\end{array}$ & $\begin{array}{l}\text { Siswa bisa saja menyontek } \\
\text { jawaban temannya }\end{array}$ \\
3. & $\begin{array}{l}\text { Menanamkan dan mengembangkan } \\
\text { keterampilan social }\end{array}$ & \\
\hline
\end{tabular}

\section{METODE PENELITIAN}

Variabel penelitian yang digunakan dalam penelitian ini terdiri atas dua variabel yaitu variabel bebas (X) dan variabel terikat $(\mathrm{Y})$. Variabel bebas (X) adalah model pembelajaran kooperatif tipe scramble, sedangkan keterampilan menulis kalimat sebagai variabel terikat $(\mathrm{Y})$. Penelitian ini merupakan penelitian True Eksperimen Design. Adapun desain yang digunakan adalah two group pretest-postest design. Dalam penelitian ini diterapkan pretest/tes awal, treatment/perlakuan, dan postest/tes akhir, agar dapat ditemukan keefektifan metodel pembelajaran scramble dalam keterampilan menulis kalimat bahasa Jerman siswa kelas X SMA Negeri 11 Makassar.

Penelitian ini difokuskan pada tes keterampilan siswa dalam menulis kalimat berita, kalimat tanya, dan kalimat perintah dengan memperhatikan kosakata, ejaan, tanda baca, dan tata bahasa yang tepat sesuai dengan tema yang disajikan, yaitu "die Familie". Penilaian keterampilan siswa dalam menulis dinilai berdasarkan pedoman penilaian yang digunakan untuk menilai penguasaan Strukturen dalam keterampilan menulis kalimat bahasa
Jerman di SMA Negeri 11 Makassar. Skor tertinggi adalah 3 apabila kalimat ditulis dengan kaidah bahasa Jerman yang tepat dan skor 0 apabila soal tidak terjawab, sehingga apabila semua kalimat (20 nomor) ditulis sesuai dengan kaidah bahasa Jerman, maka skornya adalah 60 .

Populasi yang menjadi objek dalam penelitian ini adalah siswa kelas XI SMA Negeri 11 Makassar berjumlah 300 siswa yang terdiri atas 10 kelas dengan jumlah siswa tiaptiap kelas 30 orang. Pengambilan sampel dilakukan dengan teknik random sampling (sampel acak) yaitu mengundi populasi yang ada, kemudian terpilihlah dua kelas yakni kelas XI IPA 1 sebagai kelas eksperimen dan kelas XI IPA 2 sebagai kelas kontrol dengan jumlah siswa masing-masing kelas 30 orang.

Teknik pengumpulan data dalam penelitian ini menggunakan instrumen berupa tes menulis kalimat yang diberikan kepada siswa. Bentuk tes yang digunakan dalam penelitian ini adalah tes menjawab soal berjumlah 20 soal yang terdiri atas kalimat berita, kalimat tanya, dan kalimat berita dengan memperhatikan kosakata, tanda baca, dan tata bahasa sesuai dengan kaidah bahasa Jerman. Data atau hasil tes yang telah 
terkumpul dianalisis menggunakan uji-t. Namun, sebelum dilakukan uji hipotesis, terlebih dahulu dilakukan uji normalitas dan uji homogenitas dengan menggunakan tabel $\mathrm{Z}$-score dan chi kuadrat.

\section{PEMBAHASAN}

\section{Data Pre Test}

\begin{tabular}{lrr}
\multicolumn{1}{c}{ Data } & hasil & frekuensi nilai \\
pretest & kelas & eksperimen
\end{tabular}
menunjukkan bahwa terdapat 13 siswa atau $43,3 \%$ yang memperoleh nilai dengan rentangan $43-48,3$ atau $10 \%$ yang memperoleh nilai dengan rentangan $49-54,3$ atau $10 \%$ siswa yang memperoleh nilai dengan rentangan $55-60,4$ siswa atau $13,3 \%$ yang memperoleh nilai dengan rentangan $61-66,5$ siswa atau $16,6 \%$ yang memperoleh nilai dengan rentangan $67-72,2$ siswa atau $6,7 \%$ yang memperoleh nilai dengan rentangan $73-78$.

Maka dari itu, dapat disimpulkan bahwa frekuensi tertinggi terdapat pada rentan 43-48 dengan jumlah 13 siswa atau 43,3\% dan frekuensi terendah terdapat pada rentan 73-78 dengan jumlah 2 siswa atau $6,7 \%$.

Sedangkan, data hasil frekuensi dan persentase nilai pretest kelas kontrol menunjukkan bahwa terdapat 5 siswa atau $16,6 \%$ yang memperoleh nilai dengan rentangan 43 - 48, 2 siswa atau $6,7 \%$ yang memperoleh nilai dengan rentangan 49 - 54, 6 siswa atau $20 \%$ yang memperoleh nilai dengan rentangan 55 - 60, 6 siswa atau $20 \%$ yang memperoleh nilai dengan rentangan
61 - 66, 9 siswa atau $30 \%$ yang memperoleh nilai dengan rentangan 67 - 72, dan 2 siswa atau 6,7\% yang memperoleh nilai dengan rentangan 73 - 78. Dengan demikian, dapat disimpulkan bahwa frekuensi tertinggi terdapat pada rentan $67-72$ dengan jumlah 9 siswa atau $30 \%$ dan frekuensi terendah terdapat pada rentan 49 - 54 dan 73 - 78 dengan jumlah 2 siswa atau $6,7 \%$.

\section{Data Post Test}

Data hasil frekuensi dan persentase nilai posttest kelas eksperimen menunjukkan bahwa terdapat 8 siswa atau 26,6\% yang memperoleh nilai dengan rentangan 55 - 61, 6 siswa atau 20\% yang memperoleh nilai dengan rentangan 62 - 68, 6 siswa atau $20 \%$ yang memperoleh nilai dengan rentangan 69 - 75, 4 siswa atau $13,3 \%$ yang memperoleh nilai dengan rentangan 76 - 82, 2 siswa atau $6,7 \%$ yang memperoleh nilai dengan rentangan 83 - 89, dan 4 siswa atau 13,3\% yang memperoleh nilai dengan rentangan $90-96$.

Maka dari itu, dapat disimpulkan bahwa frekuensi tertinggi terdapat pada rentan $55-61$ dengan jumlah 8 siswa atau 26,6\% dan frekuensi terendah terdapat pada rentan $83-89$ dengan jumlah 2 siswa atau $6,7 \%$.

Berdasarkan data hasil frekuensi dan persentase nilai pretest kelas kontrol menunjukkan bahwa terdapat 7 siswa atau $23,3 \%$ yang memperoleh nilai dengan rentangan 43 - 49, 3 siswa atau $10 \%$ yang 
memperoleh nilai dengan rentangan 50 - 56, 3 siswa atau $10 \%$ yang memperoleh nilai dengan rentangan 57 - 63, 4 siswa atau $13,3 \%$ yang memperoleh nilai dengan rentangan 64 - 70, 8 siswa atau $26,6 \%$ yang memperoleh nilai dengan rentangan 71 - 77, 5 siswa atau 16,6\% yang memperoleh nilai dengan rentangan $78-84$.

Maka dari itu, dapat disimpulkan bahwa frekuensi tertinggi terdapat pada rentan $71-77$ dengan jumlah 8 siswa atau $26,6 \%$ dan frekuensi terendah terdapat pada rentan 50 - 56 dan 57 - 63 dengan jumlah 3 siswa atau $10 \%$.

\section{Uji Hipotesis}

Berdasarkan analisis Z-Score, diperoleh nilai rata-rata pretest keterampilan menulis kalimat siswa kelas XI IPA 5 sebagai kelas eksperimen yaitu 55,7 dengan nilai tertinggi 78 dan nilai terendah 43 , sedangkan. Sedangkan nilai rata-rata pretest keterampilan menulis kalimat siswa kelas XI IPA 1 sebagai kelas kontrol yaitu 61,1 dengan nilai tertinggi 78 dan nilai terendah 43.

Berdasarkan uji hipotesis, hasil posttest menunjukkan bahwa penggunaan model pembelajaran kooperatif tipe scramble memiliki keefektifan dalam keterampilan menulis kalimat siswa. Hal ini dapat dilihat dari perolehan nilai rata-rata (mean) posttest kelas eksperimen yaitu 71,53 dengan perolehan nilai terendah 55 dan nilai tertinggi 97. Sementara kelas kontrol yang belajar tanpa menggunakan model pembelajaran kooperatif tipe scramble tidak mengalami peningkatan nilai yang signifikan. Hal ini dapat dilihat dari perolehan nilai rata-rata posttest kelas kontrol yaitu 41,17 dimana perolehan nilai terendah 43 dan nilai tertinggi 84. Dengan demikian nilai mean posttest kelas eksperimen lebih besar dari pada kelas kontrol. Hasil analisis uji hipotesis di atas dilanjutkan dengan uji-t. Hasilnya adalah $t_{\text {hitung }}$ kelas eksperimen $=11,24$ sementara $t_{\text {tabel }}$ $=2,002$, jadi $t_{\text {hitung }}>\mathrm{t}_{\text {tabel }}$ $(11,24>2,002)$.

Dengan demikian maka $\mathrm{H}_{0}$ yang berbunyi tidak ada perbedaan yang signifikan antara keterampilan menulis kalimat bahasa Jerman siswa yang diajar dengan model pembelajaran kooperatif tipe scramble dan siswa yang tidak diajar dengan model pembelajaran kooperatif tipe scramble dalam keterampilan menulis kalimat bahasa Jerman siswa kelas XI SMA Negeri 11 Makassar ditolak. Konsekuensi dari penolakan $\mathrm{H}_{0}$, maka $\mathrm{H}_{1}$ yang berbunyi ada perbedaan yang signifikan antara keterampilan menulis kalimat bahasa Jerman siswa yang diajar dengan model pembelajaran kooperatif tipe scramble dan siswa yang tidak diajar dengan model pembelajaran kooperatif tipe scramble dalam keterampilan menulis kalimat bahasa Jerman siswa kelas XI SMA Negeri 11 Makassar diterima.

$$
\text { Hasil penelitian ini }
$$

menemukan bahwa pembelajaran 
model pembelajaran kooperatif tipe scramble ini efektif dalam keterampilan menulis kalimat bahasa Jerman siswa kelas XI SMA Negeri 11 Makassar. Hal ini sejalan dengan teori yang dikemukakan oleh Arifin, Hamonangan (2013:2) bahwa model pembelajaran kooperatif tipe scramble merupakan sebuah upaya pembelajaran yang melibatkan diskusi siswa dalam menemukan jawaban yang tepat dengan cermat sehingga siswa merasa belajar bukan sebuah beban dan merasa tertantang untuk memecahkan soal yang diberikan.

\section{KESIMPULAN}

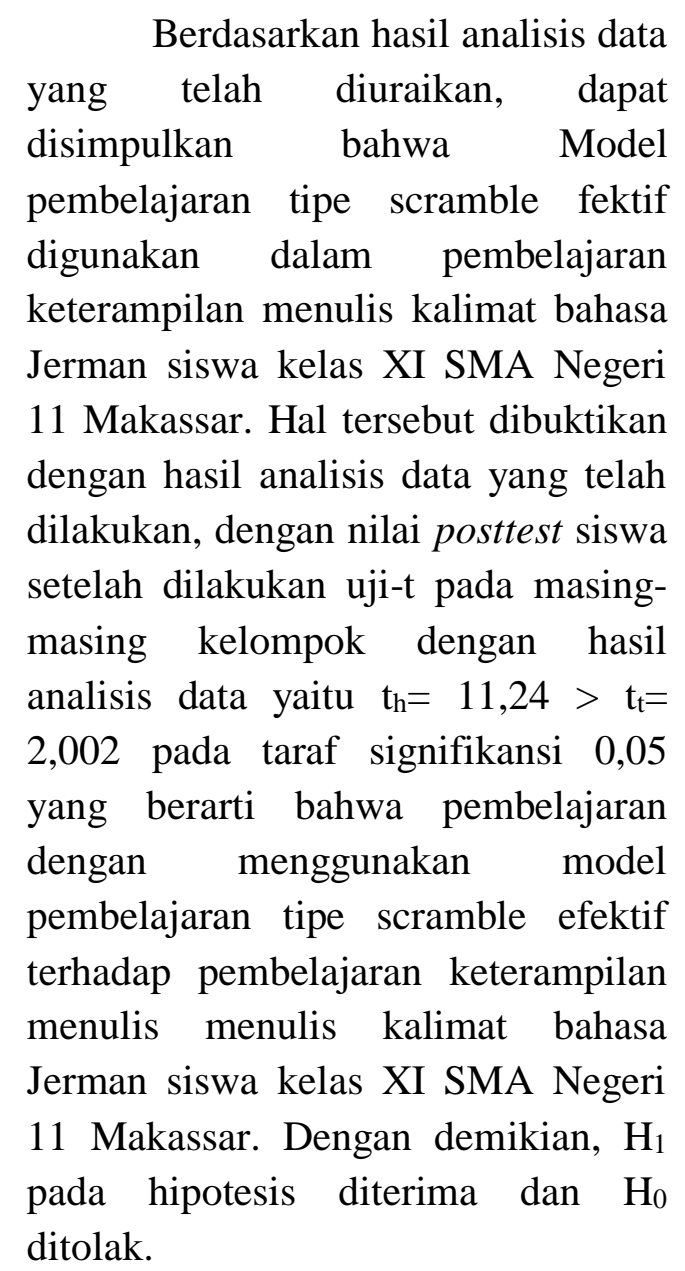

\section{DAFTAR PUSTAKA}

Alfrida. 2014. Keefektivan model pembelajaran kooperatif Scramble terhadap penguasaan Strukturen dalam keterampilan menulis kalimat bahasa Jerman siswa kelas XII SMA Negeri 2 Rantepao Kabupaten Toraja Utara. Skripsi: UNM FBS Makassar

Arifin, E. Zaenal dan Tasai, S. Amran. 2010. Cermat Berbahasa Indonesia untuk Perguruan Tinggi.Jakarta : Akademi Pressindo.

Artini, A. dkk. 2014. Pengaruh Model Pembelajaran Scramble Berbantuan Media Semi Konkret Terhadap Hasil Belajar IPS Siswa Kelas V SD Gugus Kapten Kampiong Sujana.E-Journal PGSD Vol: 2 No: 1. Universitas Pendidikan Ganesha. Diakses Pada Tanggal 14 April 2014..

Efendi, Andriani. 2011. Kemampuan Menulis Karangan Sederhana Bahasa Jerman Siswa Kelas X SMAN 1 Polongbangkeng Utara Kabupaten Takalar. Skripsi: UNM FBS Makassar

Fitriani, Ramadhani. 2010. Kemampuan Menulis Karangan Sederhana Bahasa Jerman Siswa Kelas XI SMAN 5 Makassar. Skripsi: UNM FBS Makassar.

Komalasari, Kokom. 2013. Pembelajaran Kontekstual Konsep dan Aplikasi. Bandung: PT Refika Aditama. 
Supardi. 2013. Aplikasi Statistika dalam Penelitian. Jakarta: Smart.

Suprijono, Agus. 2009. Cooperative Learning Teori dan Aplikasi PAIKEM. Yogyakarta: Pustaka Pelajar.
Tangkilisan, Hessel Nogi S. 2005. Manajemen Publik. Jakarta: Grasindo.

Tarigan, Henry Guntur. 2008. Menulis Sebagai Suatu Keterampilan Berbahasa. Bandung: Angkasa. 